\title{
Eligibility and exclusion of hemochromatosis patients as voluntary blood donors
}

\author{
M Levstik MD, PC Adams MD FRCPC
}

M Levstik, PC Adams. Eligibility and exclusion of hemochromatosis patients as voluntary blood donors. Can J Gastroenterol $1998 ; 12(1): 61-63$.

BACKGROUND: Hereditary hemochromatosis patients are excluded in many countries as voluntary blood donors. In 1991, changes in the Canadian Red Cross policy allowed healthy hemochromatosis patients to become voluntary donors.

STUDY DESIGN AND METHODS: The medical histories of 208 hemochromatosis patients were evaluated for eligibility for blood donation from a large prospective database of hemochromatosis patients. A survey that determined the success or exclusion of 81 patients for blood donation and the reasons for their exclusion based on Canadian Red Cross donor exclusion criteria was analyzed.

RESULTS: Of 208 hemochromatosis patients, 140 (67\%) were eligible for blood donation. Criteria for exclusion were other illnesses excluded by Canadian Red Cross criteria and the use of contraindicated medications. Fifty-one per cent of patients had attempted to donate blood, with only $7 \%$ being successful.

CONCLUSIONS: A large number of potential blood donors are excluded from blood donation inappropriately despite changes in eligibility criteria to the contrary. Further public and health education is needed to increase awareness and, thus, increase blood donation by potential donors.

Key Words: Hemochromatosis, Phlebotomy, Transfusion, Venesection

\section{Admissibilité et exclusion des patients atteints d'hémochromatose en tant que donneurs de sang}

DONNÉES DE DÉPART : Dans de nombreux pays, les patients atteints d'hémochromatose ne sont pas autorisés à donner de leur sang. En 1991, les changements apportés à la politique de la Croix-Rouge canadienne ont permis aux patients atteints d'hémochromatose mais par ailleurs en bonne santé de donner de leur sang.

MODÈLE DE L'ÉTUDE ET MÉTHODES : Les antécédents médicaux de 208 patients atteints d'hémochromatose ont été évalués pour déterminer s'ils pouvaient donner de leur sang, à partir d'une importante base de données prospective sur des patients atteints de la maladie. On a procédé à l'analyse d'un sondage sur l'acceptation ou l'exclusion de 81 patients en tant que donneurs et les raisons de leur exclusion en fonction des critères de la Croix-Rouge.

RÉSULTATS : Parmi les 208 patients, 140 (67\%) étaient admissibles. Les critères d'exclusion étaient d'autres maladies et l'emploi de médicaments contre-indiqués. Cinquante-et-un pour cent des patients ont tenté de donner du sang , $7 \%$ seulement ont réussi. CONCLUSIONS : Un important nombre de donneurs de sang potentiels sont exclus pour de mauvaises raisons et ce, malgré les changements apportés aux critères d'admissibilité. Il faut accroître la sensibilisation du public et des professionnels de la santé pour donner à d'autres donneurs potentiels la possibilité de faire don de leur sang.
B ecause hemochromatosis patients are treated by periodic venesection to remove iron they have the potential to become regular blood donors (1). The number of patients who have successfully donated blood since the guidelines of the Canadian Red Cross were expanded in 1991 to include healthy hemochromatosis patients is unknown. Exclusion criteria of the Canadian Red Cross are diabetes, hyperten- sion on medication, cirrhosis, skin discolouration and positive testing for hepatitis B (hepatitis B surface antigen), hepatitis $C$ (antihepatitis $C$ virus) and human immunodeficiency virus.

In this study, we review the potential eligibility of hemochromatosis patients and determine by survey the actual success of hemochromatosis patients in donating blood.

Department of Medicine, University of Western Ontario, London, Ontario

Correspondence: Dr Paul C Adams, London Health Sciences Centre, University Campus, PO Box 5339, 339 Windermere Road, London,

Ontario N6A 5A5. Telephone 519-663-3513, fax 519-663-3232, email padams@julian.uwo.ca

Received for publication June 3, 1997. Accepted January 16, 1998. 


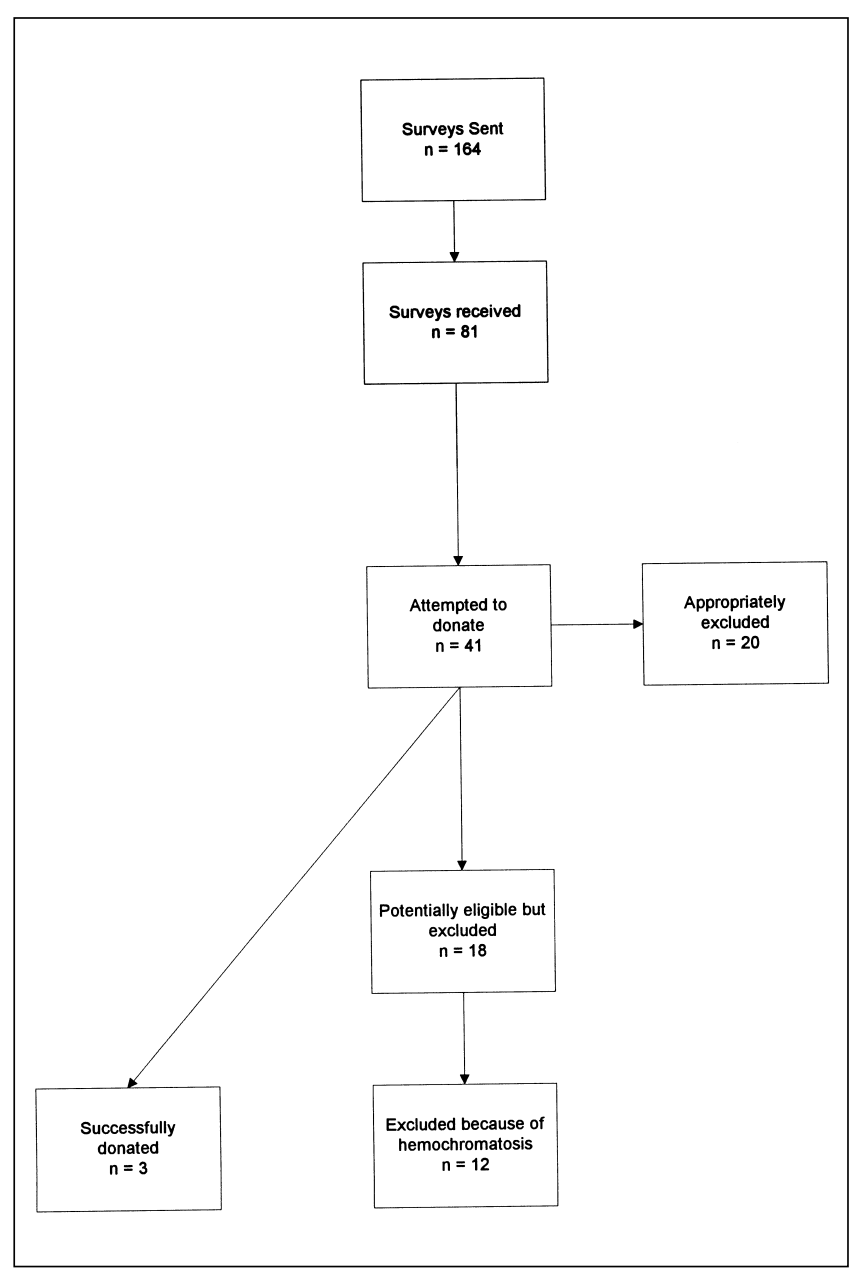

Figure 1) Method for obtaining data for a survey that determined the success or exclusion of hemochromatosis patients for blood donation

\section{PATIENTS AND METHODS}

A database comprising 208 hemochromatosis homozygous patients diagnosed at this centre since 1960 was reviewed to assess potential eligibility of patients to donate blood. This represents all known living hemochromatosis patients in the database. This database includes information on signs and symptoms of hemochromatosis, biochemical and liver biopsy data, and concomitant illness.

A survey was sent to available homozygous patients in 1996 to determine their success in donating blood. This study was approved by the Human Ethics Committee of the University of Western Ontario, London, Ontario. The information on blood donation was part of an American survey on hemochromatosis sponsored by the Centers for Disease Control and Prevention, Atlanta, Georgia. Because American patients are ineligible to be voluntary blood donors, this study was conducted on hemochromatosis patients diagnosed at this medical centre. If patients provided more than one explanation for exclusion, the reason that was a valid contraindication by Canadian Red Cross criteria was considered the reason for ineligibility. Information on the use of the donated blood was not available.

\section{RESULTS}

Sixty-seven per cent (140 of 208) of hemochromatosis patients were potential donors. Sixty-four per cent of patients were classified as ineligible because of diabetes, $18 \%$ because they were older than 71 years of age, $9 \%$ because of chronic medication use, $2 \%$ because of cirrhosis and $2 \%$ because of malignancy. Of this population 6\% (13 of 208) had been voluntary blood donors before the diagnosis of hemochromatosis.

In the initial mailing, the survey was sent to 164 patients who were thought to be alive at the time of the survey. Follow-up telephone calls determined that many patients were no longer at their original address. Eighty-one homozygous patients responded to the survey. This may have resulted in a bias in favour of patients who have participated in voluntary blood donation. This is suggested by the high percentage of patients who attempted to donate blood (51\%) compared with the percentage of the general population that donates blood (estimated at $5 \%$ by Canadian Red Cross). Of these 81 patients, $51 \%$ ( 41 of 81 ) were potentially eligible donors. Fifty-one per cent (41 of 81 ) had attempted to donate blood, but only $7 \%$ (3 of 41) were successful. Of the patients who attempted to donate and were excluded, 44\% (18 of 41) would have been eligible according to the above criteria (Figure 1). A diagnosis of hemochromatosis was the reason for exclusion in 67\% (12 of 18) (Figure 1).

\section{DISCUSSION}

Hereditary hemochromatosis is a genetic disease with no evidence of transmission by blood transfusion. Despite changes in Canadian Red Cross policy in 1991, it is still uncommon for a hemochromatosis patient to donate blood successfully, possibly for the following reasons:

1. lack of awareness at blood donor clinics of the eligibility of hemochromatosis patients;

2. lack of awareness of hemochromatosis patients about the possibility of being a voluntary blood donor; and

3. existence of appropriate reasons for exclusion in hemochromatosis patients, including diabetes, cirrhosis and concomitant use of medications.

It is not feasible for weekly therapeutic venesections to be done at voluntary blood donor clinics in Canada because a patient can only donate once every 56 days. However, it is possible for iron depleted hemochromatosis patients to donate every three months as maintenance therapy on a long term basis. The historical reasons for the exclusion of hemochromatosis patients as voluntary blood donors are that therapeutic venesections cannot be used for voluntary blood donation and the unproven concern that the donated blood may have deleterious effects in the donor. In some countries patients incur significant costs for therapeutic venesections and may seek to avoid these costs. There is concern that donors motivated by reasons other than altruistic ones might misrepresent important historical data $(2,3)$. Healthy hemochromatosis patients have been accepted as donors in Can- 
ada and Sweden, and in regional centres in California and Florida (4). We strongly support the position of the Canadian Red Cross to allow healthy hemochromatosis patients to donate blood and encourage other countries to adopt similar policies. Decision analysis studies have demonstrated that reducing the cost of venesection therapy by allowing patients to be voluntary donors has a significant effect on the cost effectiveness of screening for hemochromatosis $(5,6)$.

\section{REFERENCES}

1. Worwood M, Darke C, Trenchard P. Hereditary haemochromatosis and blood donation. BMJ 1991;302:593.

2. Grindon AJ. Blood donation from patients with hemochromatosis. JAMA 1993;270:880. (Lett)

3. Penning HL. Blood donation by patients with hemochromatosis. JAMA 1993;270:2929.
Education of hemochromatosis patients and blood donor clinic personnel could greatly increase the donation rate in this population of regular donors.

ACKNOWLEDGEMENTS: Dr Mark Levstik acknowledges the support of a Canadian Association for the Study of the Liver Hepatology Fellowship sponsored by Glaxo Wellcome Inc.

4. Adams PC, Gregor JC, Kertesz AE, Valberg LS. Screening blood donors for hereditary hemochromatosis: decision analysis model based on a thirty-year database. Gastroenterology 1995;109:177-88.

5. Adams PC, Kertesz A, Valberg LS. Screening for hemochromatosis in children of homozygotes: prevalence and cost-effectiveness. Hepatology 1995;22:1720-7. 


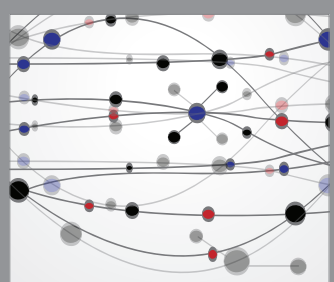

The Scientific World Journal
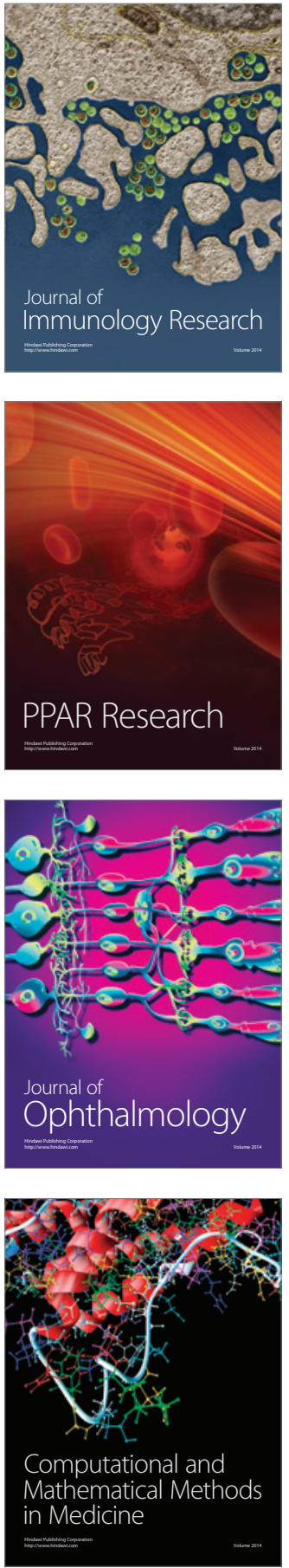

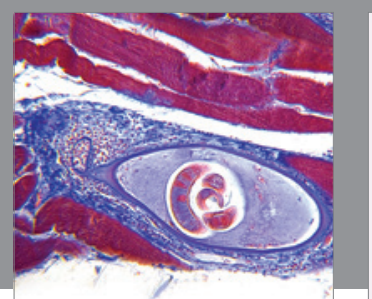

Gastroenterology Research and Practice

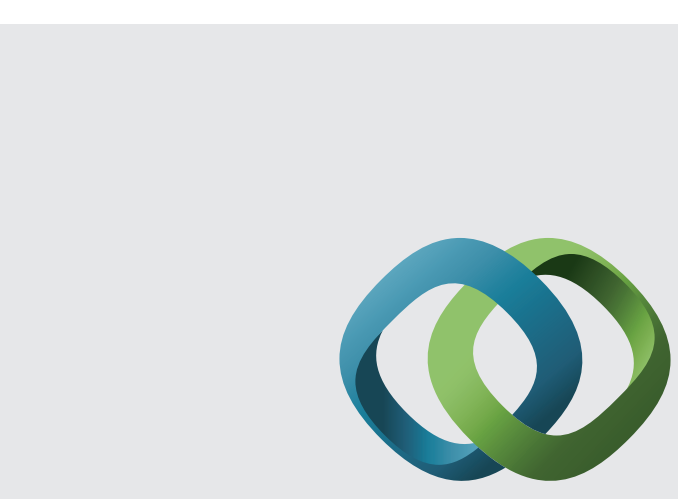

\section{Hindawi}

Submit your manuscripts at

http://www.hindawi.com
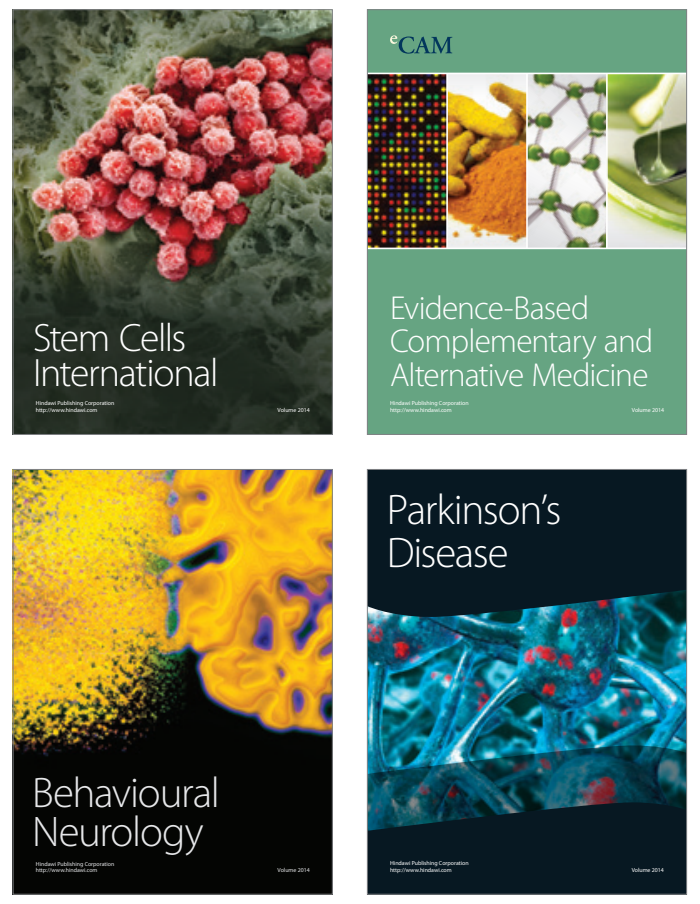
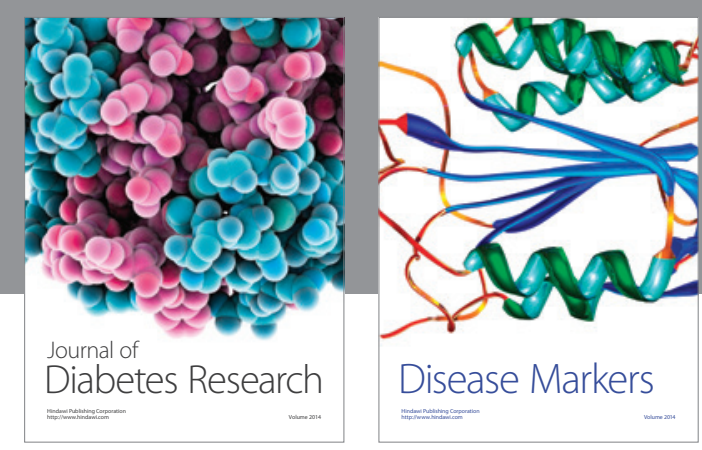

Disease Markers
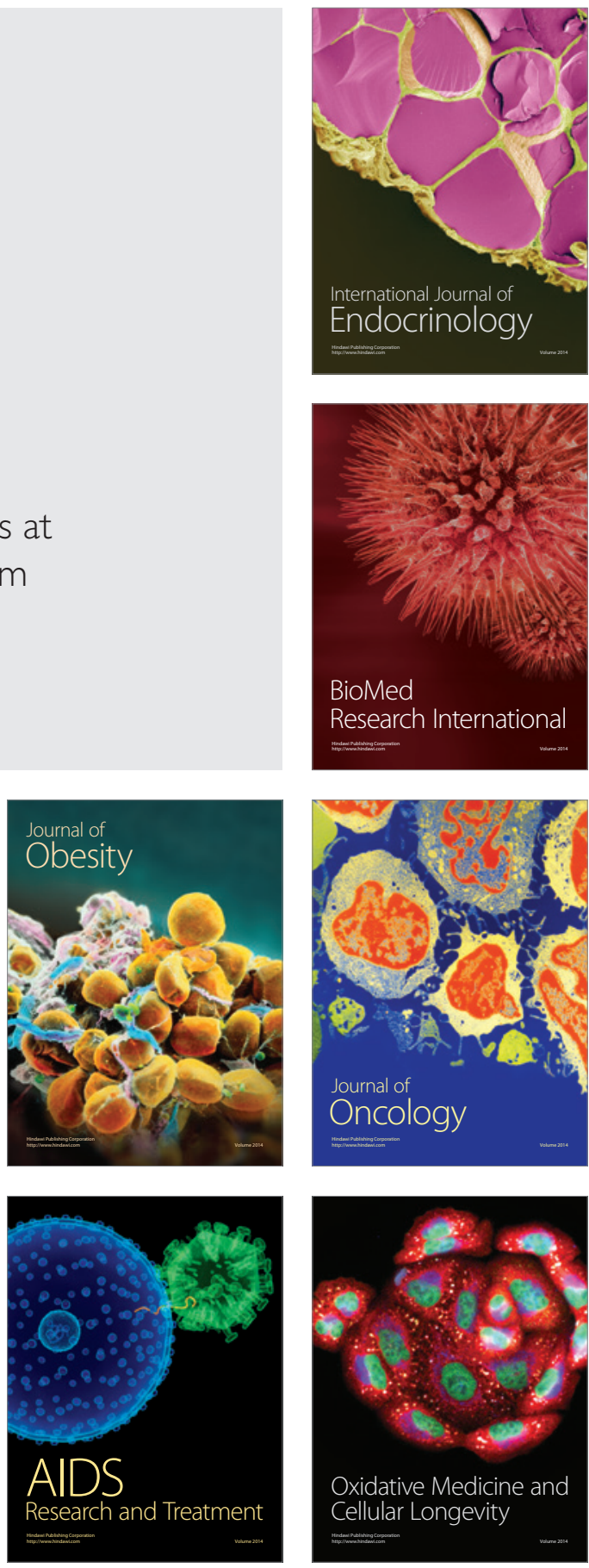